\title{
LUT
}

University

\section{Maintenance Education in Engineering Programs on Bachelor and Master Level: Evidence from Finland and Sweden}

\author{
Kans Mirka, Metso Lasse
}

This is a Final draft

version of a publication

published by Springer

in Liyanage, J., Amadi-Echendu, J., Mathew, J. (eds) Engineering Assets and Public Infrastructures in the Age of Digitalization. Lecture Notes in Mechanical Engineering.

DOI: 10.1007/978-3-030-48021-9_52

Copyright of the original publication: () Springer Nature Switzerland AG 2020

Please cite the publication as follows:

Kans, M., Metso, L. (2020). Maintenance Education in Engineering Programs on Bachelor and Master Level: Evidence from Finland and Sweden. In: Liyanage, J., Amadi-Echendu, J., Mathew, $\mathrm{J}$. (eds) Engineering Assets and Public Infrastructures in the Age of Digitalization. Lecture Notes in Mechanical Engineering. Springer, Cham. DOI: 10.1007/978-3-030-48021-9_52

This is a parallel published version of an original publication. This version can differ from the original published article. 


\title{
Maintenance education in engineering programs on bachelor and master level: evidence from Finland and Sweden
}

\author{
Mirka Kans ${ }^{1}$, Lasse Metso ${ }^{2}$
}

\begin{abstract}
This paper discusses the need for maintenance related training in higher education and investigates the maintenance related education offered by engineering programs in Finland and Sweden. Main study objects are Finnish and Swedish Mechanical and Industrial engineering programs on both bachelor and master level. The study covers, for the selected programs, full programs in maintenance, single courses and parts of courses in which maintenance plays a role. In Finland there are in total 42 universities and applied science schools offering 115 programs within Mechanical or Industrial engineering. Of those, 17 programs contain some sort of maintenance related training. The corresponding figures for Sweden are 23 universities and applied science schools offering 87 programs within Mechanical or Industrial engineering, and 10 of these programs contains maintenance related education. For reviewing the educational contents, data was collected from course syllabuses; for each course the content and expected learning outcomes were analysed and categorised. The maintenance related education in the studied programs is in general low; less than $15 \%$ offer maintenance courses. The content in the maintenance related courses differs greatly: concept of maintenance, information systems in maintenance, reliability, life-cycle management, condition monitoring and management of maintenance are covered. For increasing the maintenance topics in higher education, the development of appropriate study material and joint online courses are suggested.
\end{abstract}

\footnotetext{
${ }^{1}$ M. Kans $(\bowtie)$

Department of Mechanical Engineering, Linnaeus University, Växjö, Sweden e-mail: mirka.kans@lnu.se

${ }^{2}$ L. Metso

Lappeenranta University of Technology, Industrial Engineering and Management,

Lappeenranta, Finland

email: lasse.metso@lut.fi
} 


\section{Introduction}

Engineers of today require a holistic understanding of products and processes. Consequently, engineering education should provide the possibility to acquire these kind of competences. The worldwide initiative CDIO (Conceive-Design-Implement-Operate) was developed in collaboration with academia, industry and students for supporting the realisation of a modern engineering education, Crawley et al. (2008). According to CDIO, the engineering students have to understand both engineering fundamentals and the full product life cycle, from the conceiving of an idea to the operations of the finished product. A mechanical engineering student for instance needs to understand not only how to design and construct products, but also how the products are operated and maintained. Similarly, an industrial engineering student needs understanding of how to optimise the whole business, from production and logistics to maintenance and asset management. This paper will focus on education regarding the operations and maintenance phase.

The topic of maintenance related education in engineering programs and maintenance training is not well researched: only four publications were found during a structured review. In Heilman and Heilman (2011) findings from an interview survey of maintenance training in the Finnish forest industry stress the importance of competence development for current as well as new employees. However, this article does not address the higher education and how this should be designed for preparing prospective new employees. Lai (2010) surveyed building-related education in Hong Kong, and no program was found that focused on operations and maintenance of buildings. Lai reports on strong interest in such education amongst the respondents. Knezevic (1997) describes a postgraduate education program within maintenance, and the master thesis by Nerland (2010) describes a survey conducted on maintenance vocational training in Norwegian industry in collaboration with the Norwegian Maintenance Organization. The author concludes that the skills level was satisfying but with improvement possibilities, and that maintenance education and training should be developed further on high school, higher education as well as on post-training level.

In this paper, two main research questions will be addressed: What should the engineering students know about maintenance (knowledge and skills), and What kind of maintenance related training (what and how) do the mechanical and industrial engineering students get during their education? For answering question one a literature addressing engineering education as well as the standard EN15628:2014 Maintenance, Qualification of maintenance personnel and the European Federation of National Maintenance Societies (EFNMS) instructions and certificates of requirements for maintenance professionals will be utilized. For addressing question two, the Finnish and Swedish education systems are presented, and thereafter studies regarding engineering education that comprises maintenance training conducted in the previously mentioned countries are accounted for. 
M Kans L Metso - Maintenance education in engineering programs

\section{Maintenance knowledge and skills}

This section describes the skills and knowledge requirements for the higher education level as described in literature and standards. EFNMS has developed curricula for maintenance training for the maintenance technician as well as for the maintenance manager. According to EFNMS (1998), a maintenance manager should be skilled in following topics: Management and, Reliability performance of production plants, Maintenance information systems, and Maintenance methods and techniques. A curriculum is proposed based on the EFNMS requirements in Nerland (2010) for maintenance training on high school, higher education and posttraining level. The headings suggested for the higher education level are: Maintenance objectives and strategies, Maintenance terminology, Addressing failures, Operational safety and reliability, Condition based maintenance, Health, safety and environment, Modern maintenance concepts, Indicators, Maintenance logistics, Maintenance software, Economy, organization, Teamwork and communication, $\mathrm{RCM}$, and Proactive and predictive maintenance. The postgraduate education program within maintenance denoted the MIRCE academy described in Knezevic (1997) consisted of following modules: Maintenance in life cycle engineering, Mathematics of maintenance, Methods and tools of maintenance analysis, Reliability and safety, Maintainability engineering, Supportability engineering, Economics of maintenance, Maintenance integration, Design for maintenance, and Maintenance management. The standard EN 15628 (2014) defines seven competence areas of a maintenance manager: 1) to define and develop maintenance policies according to company strategies; 2) to define processes and tools to support maintenance tasks; 3) to define, manage and develop the organizational model of maintenance; 4) to ensure the levels of availability, reliability, maintainability, supportability, safety and quality required for the entire useful life of assets; 5) to ensure appropriate management and continuous improvement of maintenance; 6) to ensure and control the compliance with maintenance and company budget, the respect of the planned maintenance tasks and the proper condition of assets; 7) to define strategies, policies and criteria for performance management of contractors and for the definition of maintenance materials requirements. Table 1 summarises the knowledge and skills of a maintenance manager according to the literature and standards.

Table 1. Summary of maintenance knowledge and skills of a maintenance manager

\begin{tabular}{lllll}
\hline Topics & EFNMS & Nerland & Knezevic & EN15628 \\
\hline Terms and standards & & $\mathrm{x}$ & & $\mathrm{x}$ \\
\hline Management and organisation & $\mathrm{x}$ & $\mathrm{x}$ & $\mathrm{x}$ & $\mathrm{x}$ \\
\hline Maintenance systems and planning & $\mathrm{x}$ & $\mathrm{x}$ & $\mathrm{x}$ & \\
\hline Maintenance engineering & $\mathrm{x}$ & $\mathrm{x}$ & $\mathrm{x}$ & $\mathrm{x}$ \\
\hline Reliability engineering & $\mathrm{x}$ & $\mathrm{x}$ & $\mathrm{x}$ & $\mathrm{x}$ \\
\hline Heath, safety and environment & & $\mathrm{x}$ & $\mathrm{x}$ & $\mathrm{x}$ \\
\hline Maintenance economics & $\mathrm{x}$ & & & \\
\hline
\end{tabular}




\section{The Swedish and Finnish education system}

Both the Swedish and Finnish higher education are structured according to the Bologna Process. The first cycle covers years 1-3, the second cycle years 4-5, and the third cycle years 6-9 (PhD level). The workload needed for one full year of studies is correspondent to 60 credits. In Sweden, all degrees are issued in accordance with the The Higher Education Ordinance, Swedish Council for Higher Education (2013). The general qualification for the first cycle is the Degree of Bachelor, which fulfils the general admission requirements to second-cycle studies, i.e. qualification within the first cycle of at least 180 credits. The second cycle general qualifications are the Degree of Master. Both a one-year master (60 credits) and a twoyear master degree (120 credits) exists. A Degree of Doctor is normally achieved after four years full-time studies in Sweden. In addition to the general qualifications, a number of professional qualifications are awarded, amongst them two within engineering. The Degree of Bachelor in Engineering is issued after three years of studies. A five year qualification, Degree of Master in Engineering, is also issued. The latter is a popular engineering programme in Sweden, and the admission requirements are higher than for the general qualifications (more advanced maths and science is required). 49 higher education institutions exist in Sweden. Of these, 16 are full universities and 33 university colleges. Main part of the institutions are public, and the education is publicly funded, with few exceptions. In 2018, 22 of these institutions offer 140 Bachelor of engineering programs, and 15 institutions offer 145 Master of engineering programs, Swedish Council for Higher Education (2018). Of the 140 Bachelor of engineering programs, 37 are within the subject area Mechanical engineering, and 13 within Industrial engineering. 18 and 19 are the corresponding figures for the Masters of engineering programs. In the section 3.1 the maintenance related education in these 87 programs is described.

The Finnish higher education system is governed and financed by the Ministry of Education and Culture (Ministry of Education and Culture). The degrees offered at universities of applied sciences are Bachelor's degrees (210-270 credits, 3,5-4,5 years) and Master's degrees (60- 90 credits, 2 years). In universities, the degrees are Bachelor's degrees (180 credits, 3 years), Master's degrees (120 credits, 2 years), and third-cycle postgraduate degrees. The calculated timeframe to complete a doctorate is four years of full-time studies. The Finnish higher education system is composed of 40 universities and universities of applied sciences, most of which operate under the Ministry of Education and Culture. In total, the administrative branch of the Ministry of Education and Culture manages 14 universities and 23 universities of applied sciences. The three exceptions are Åland Univeristy of Applied Sciences, the Police University College and the National Defence University, which operate under the Ministry of the Interior. In 2018, 30 of these institutions offer 228 Bachelor of engineering programs, and 19 institutions offer 122 Master of engineering programs. Of the bachelor of engineering programs 49 are in Mechanical engineering, and 21 in Industrial engineering. Of the master of engineering programs 20 are 
M Kans L Metso - Maintenance education in engineering programs

within the Mechanical engineering and 25 in Industrial engineering. In the section 3.2 the maintenance related education in these 115 programs is described (Ministry of Education and Culture, Opintopolku).

\subsection{Maintenance education in Mechanical engineering and In- dustrial engineering programs in Sweden}

For collecting information regarding Swedish conditions, three types of sources were used: 1) The web portal www.antagning.se provided by Swedish Council for Higher Education. Education programs and courses open for admission are announced here. The search engine was used for finding available engineering programs with start date 2018 . This resulted in a first list of totally 110 programs, including duplicates. 2) The official University web pages. The main investigation was made on the university web pages. First, a broad search using keywords maintenance and reliability was conducted. All hits indicating programs and courses were investigated further, and the program and course syllabuses were downloaded or copied from the web page. Thereafter, the mechanical and industrial engineering programs were investigated in detail using the headings, subpages and search engines provided for that purpose. 3) Phone calls to program responsibles. Programs that have undergone recent changes or where it is mentioned in the syllabus that maintenance related skills are acquired but where no maintenance related course was to be found were investigated further by inquiring the program responsible through phone.

Maintenance related education is found in ten of the 87 programs. The scope of maintenance related education differs greatly, from being a topic in a course to whole programs focusing on maintenance management and engineering. Even if few Mechanical engineering programs on bachelor level contain maintenance related education, two programs exist which are dedicated to the topic; the Bachelor Programme in Maintenance Engineering at Luleå University of Technology and the Degree Programme in Industrial Technology and Production Maintenance at Royal Institute of Technology. These programs constitutes of courses in the maintenance area of 74 credits and 57 credits respectively. The program in Luleå has been offered for over a decade and covers various aspects of maintenance and its management, but also reliability engineering and life cycle costing. The program offered by Royal Institute of Technology starts in 2018 and has a sustainability focus, and covers concepts of maintenance, reliability and dependability, and in addition courses covering the digital and automated factory. In addition to these programs, the Manufacturing engineering program at University of Skövde includes a course in maintenance and operation reliability. This course covers the concepts of maintenance and reliability, and especially the economic aspects and improvement work. In the fiveyear master variants, two programs offered at Mälardalen University include maintenance related courses. One covers maintenance and dependability while the other course is regarding Total quality Management, Risk management and Lean 
production. In total five Industrial engineering programs include maintenance related courses, whereas three are in bachelor programs and two in master programs. Reliability engineering is offered at Skövde University addressing reliability analysis and design, but also software quality. Reliability and maintenance are in focus in the course offered for Industrial engineering students at the bachelor program at Linnaeus University. In the economy and production technology program at Chalmers a course covering quality and reliability control is given, covering Total Quality Management, Total productive Maintenance, and Reliability Centered Maintenance. In the five year master program at Umeå University a course in reliability is offered, covering reliability theory and Markov processes. Luleå University of Technology offers a master program in Industrial and Management Engineering, and the civil engineering profile includes a course in operation and maintenance, and their applications for infrastructure. Table 2 summarizes the Swedish findings. Except for the Mechanical and Industrial engineering programs, maintenance courses are found in programs focusing on Automation engineering, Energy technology and environment, Civil engineering with railway specialisation, and Production development and management.

Table 2. Maintenance related education in Sweden, Mechanical/industrial engineering

\begin{tabular}{|c|c|c|}
\hline & Program and institution & $\begin{array}{l}\text { Maintenance } \\
\text { related educat- } \\
\text { ion (credits) }\end{array}$ \\
\hline \multirow{3}{*}{ 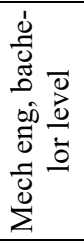 } & Manufacturing Engineer, University of Skövde & 6 \\
\hline & $\begin{array}{l}\text { Bachelor Programme in Maintenance Engineering, Luleå } \\
\text { University of Technology }\end{array}$ & 75 \\
\hline & $\begin{array}{l}\text { Degree Programme in Industrial Technology and Production } \\
\text { Maintenance, Royal Institute of Technology }\end{array}$ & 57 \\
\hline \multirow{2}{*}{ 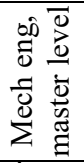 } & $\begin{array}{l}\text { Master Program in Engineering - Dependable Systems, Mä- } \\
\text { lardalen University }\end{array}$ & About 5 of $10^{*}$ \\
\hline & $\begin{array}{l}\text { Master Program in Production and product design, Mälarda- } \\
\text { len University }\end{array}$ & 7.5 \\
\hline \multirow{3}{*}{ 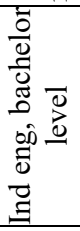 } & $\begin{array}{l}\text { Study Programme in Industrial Engineering and Manage- } \\
\text { ment, University of Gävle }\end{array}$ & 7.5 \\
\hline & $\begin{array}{l}\text { Industrial Engineering and Management, Linnaeus Univer- } \\
\text { sity }\end{array}$ & 7.5 \\
\hline & Economy and production technology, Chalmers & $\begin{array}{r}\text { About } 4 \text { of } \\
7.5^{*} \\
\end{array}$ \\
\hline \multirow{2}{*}{ 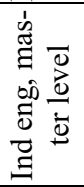 } & $\begin{array}{l}\text { Master of Science in Industrial Engineering and Manage- } \\
\text { ment, Umeå University }\end{array}$ & 7.5 \\
\hline & $\begin{array}{l}\text { Master Programme in Industrial and Management Engineer- } \\
\text { ing, profile civil engineering, Luleå University of Technol- } \\
\text { ogy }\end{array}$ & 7.5 \\
\hline
\end{tabular}

* The number of credits is an assessment based on the course syllabus 
M Kans L Metso - Maintenance education in engineering programs

\subsection{Maintenance education in Mechanical engineering and In- dustrial engineering programs in Finland}

For collecting information about Finnish conditions, following types of sources were used: 1) The web portal www.minedu.fi provided by Finnish Ministry of Education and Culture. The portal offer general information about Finnish education system. 2) The web portal https://opintopolku.fi provided by Finnish National Agency for Education and Finnish Ministry of Education and Culture. Education programs and courses open for admission are announced here. 3) The official University web pages. The main investigation was made on the university web pages. The mechanical and industrial engineering programs were investigated in detail using the headings, subpages and search engines provided for that purpose. On other programs the search was done using keywords maintenance and reliability.

Maintenance related courses are found in 17 of the mechanical engineering and industrial engineering programs offered by both universities of applied science and universities. The scope of maintenance is a part of course to a couple of courses in the same institution. Häme University of Applied Sciences has a maintenance module of 15 credits. The module is a general introduction to the core concepts of maintenance. Themes are reliability-focused maintenance, production information systems and maintenance budgets. In Kajaani University of Applied Sciences the Bachelor Programme in Production Technology offers 29 credits of maintenance courses. The content of courses are introduction to maintenance, project work, maintenance in mining, vibration and diagnostics. The University of Applied Science of Jyväskylä had in 2015 a "Service Lifecycle Management" program in master level containing in total 60 credits, but the program is no longer given. That program included 28 credits maintenance related courses. In other universities of applied science maintenance education consists of a course or a couple of courses mainly focused to bachelor level. The themes are basics of maintenance, industrial maintenance, maintenance and safety, reliability engineering and life-cycle management, preventive maintenance, CMMS, technical diagnostics, and vibration mechanics. The University of Oulu offers five maintenance related courses in different areas of industries on both master and bachelor level, 5 credit/course. The content of the courses is introduction to maintenance, maintenance of machines, building and infrastructure maintenance. Tampere university of Technology has four maintenance related courses on both bachelor and master level about condition monitoring and diagnostics. Lappeenranta University of Technology has two courses of maintenance in master level about maintenance management and costs. Other universities have only a single course or part of courses in maintenance. However, the forestry, paper technology, process technology, marine technology, mining, energy engineering, technology, communication and transport and building technologies programs have some maintenance courses in their own area of technology. Table 3 summarizes the Finnish findings in Mechanical and industrial engineering programs. 
Table 3. Maintenance related education in Finland, Mechanical/industrial engineering

\begin{tabular}{|c|c|c|}
\hline & Program and institution & $\begin{array}{l}\text { Maintenance } \\
\text { related educat- } \\
\text { ion (credits) }\end{array}$ \\
\hline \multirow{5}{*}{ 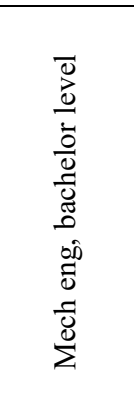 } & $\begin{array}{l}\text { Bachelor Programme in Mechanical Engineering, Tampere } \\
\text { University of Technology }\end{array}$ & \\
\hline & $\begin{array}{l}\text { Bachelor Programme in Mechanical Engineering, Karelia } \\
\text { University of Applied Sciences }\end{array}$ & 3 \\
\hline & $\begin{array}{l}\text { Bachelor Programme in Production Technology, Kajaani } \\
\text { University of Applied Sciences }\end{array}$ & 29 \\
\hline & $\begin{array}{l}\text { Bachelor Programme in Mechanical Engineering, University } \\
\text { of Oulu }\end{array}$ & 10 \\
\hline & $\begin{array}{l}\text { Bachelor Programme in Mechanical Engineering, Metropo- } \\
\text { lia University of Applied Sciences }\end{array}$ & 5 \\
\hline \multirow{3}{*}{ 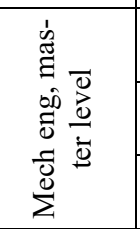 } & $\begin{array}{l}\text { Master Programme in Mechanical Engineering, University } \\
\text { of Oulu }\end{array}$ & 15 \\
\hline & $\begin{array}{l}\text { Master of Science in Mechanical Engineering, Lappeenranta } \\
\text { University of Technology }\end{array}$ & 4 \\
\hline & $\begin{array}{l}\text { Master Programme in Mechanical Engineering, Tampere } \\
\text { University of Technology }\end{array}$ & 10 \\
\hline ت & $\begin{array}{l}\text { Bachelor Programme in Automation Engineering \& Indus- } \\
\text { trial Management, Häme University of Applied Sciences }\end{array}$ & 15 \\
\hline ت्ञ & $\begin{array}{l}\text { Master of Science in Industrial Engineering and Manage- } \\
\text { ment, Lappeenranta University of Technology }\end{array}$ & \\
\hline
\end{tabular}

\section{Discussion and conclusions}

For the maintenance related education, engineering students need holistic understanding as well as subject specific knowledge. Table 1 is a comprehensive summary of relevant topics, covering maintenance terminology, system, engineering and management (subject specific themes) as well as maintenance with respect to reliability, safety, health and economy (holistic understanding). In general, maintenance has a small role in mechanical engineering and industrial engineering education in the studied countries. Most programs do not contain maintenance at all. In Sweden Luleå University of Technology and the Royal Institute of Technology and in Finland Häme University of Applied Sciences offer a larger combination of maintenance education while other institutions offer a single or a couple of courses of maintenance within the programs. The content of courses covers the basics of maintenance to advanced topics of maintenance. Maintenance skills and knowledge presented in table 1 can be covered in the maintenance-focused programs listed 
M Kans L Metso - Maintenance education in engineering programs

above, but in the single courses, maintenance skills and knowledge are only partly achieved.

The main differences between Finland and Sweden in maintenance education are the length of programs and the number of universities giving maintenance courses. In Finland, maintenance related courses are given in more universities than in Sweden. However, maintenance programs in Sweden have much wider scope and more credits than in Finland, and more courses for Industrial engineers. In Finland, a few universities have more than two courses topics about maintenance. For example, Häme University of Applied Sciences offer maintenance module of 15 credits and university of Oulu total 25 credits about maintenance topics but not a program of maintenance. Two basic courses is given in bachelor level and three courses in master level. This paper focus only mechanical engineering and industrial engineering programs, which is a delimitation. The review shows that maintenance courses are given in other programs as well - usually a single basic course and maybe some courses in their own technology e.g. about maintenance of ships, railway infrastructure or electrical systems.

The results are to be seen as a snapshot in time. While talking with colleagues at other universities, it is evident that changes are made in the programs depending on the resources and competencies available. If a person leaves the university, the ability to provide sufficient education within maintenance might be lost, resulting in changes in the curriculum. The opposite could also be seen; the Royal Institute of Technology in Sweden is for instance starting up a new program within the area. It was acknowledged in Nerland (2010) that more support is needed for maintenance related education, for instance in the form of syllabuses, teaching material and textbooks. The standard EN 15628 provides a good basis for the syllabus for maintenance related education, but from an asset management perspective, a similar syllabus covering a wider area than maintenance management and engineering might be a better alternative. As for textbooks, it is important that such are available in the native language, and on the correct level of education. Moreover, as teachers with the competence and ability to train maintenance related topics is missing in many universities, textbooks supporting the general engineering teacher in the introduction of maintenance would be needed. With sufficient and appropriate material, the probability that maintenance and reliability is included as a topic in a related course, such as one in quality management or sustainability, would increase. Another option is to provide online courses that could be incorporated into the education programs without the necessity to acquire the competence in maintenance management and engineering at the individual universities. Here, the possibilities that lies in MOOCS, Massive Open Online Courses, is promising. The MOOC could be directed either to the engineering student, or to the engineering teacher. Collaboration in developing such would be not only of national, but of international interest. 


\section{References}

Crawley E F, Brodeur D R and Soderholm D H (2008). The education of future aeronautical engineers: conceiving, designing, implementing and operating JSET 17(2) 138-51

European Federation of National Maintenance Societies (1998). The Requirements and Rules to achieve an EFNMS Certificate as a European Expert in Maintenance Management [Online document]. Accessed: http://www.efnms.eu/committees/european-certification-committee/.

Finnish Standards Association (2014). SFS-EN 15628 Maintenance. Qualification of maintenance personnel.

Heilmann, Pia and Heilmann, Jouni (2011). Competence management in maintenance: case - Finnish forest company, Management Research Review, Vol. 35 Issue: 1, pp.4-13.

Knezevic, Jezdimir (1997). Industry driven postgraduate maintenance education: MIRCE approach, Journal of Quality in Maintenance Engineering, Vol. 3 Issue: 4, pp.302-308.

Lai, Joseph H.K. (2010).Building operation and maintenance: education needs in Hong Kong, Facilities, Vol. 28 Issue: 9/10, pp.475-493.

Ministry of Education and Culture (2018). Higher education and science. http://minedu.fi/en/higher-education-and-research. Visited 2 March 2018

Nerland, Annette Smørholm (2010). Competence within Maintenance. [Master thesis]. Norges Teknisk-Naturvitenskapelige Universitet, Fakultet for Ingeniørvitenskap Og Teknologi, Institutt for Produksjons- Og Kvalitetsteknikk.

Opintopolku (2018). https://opintopolku.fi/wp/fi/. Visited 2 March 2018.

Swedish Council for Higher Education (2013). The Swedish Higher Education System. [Online document]. Accessed: https://www.uhr.se/globalassets/_uhr.se/bedomning/diploma-supplement/the_swed_high_system.pdf

Swedish Council for Higher Education (2018). Sök utbildning på alla Sveriges universitet och högskolor - Antagning.se. https://www.antagning.se/se/start. Visited: 20 February 2018. 